\title{
Epidemiology of Hookworm Infection in Itagua, Paraguay: a Cross Sectional Study
}

\author{
Nora Labiano-Abello, Jorge Canese*, Maria Eugenia Velazquez*, \\ John M Hawdon, Mark L Wilson**/+, Peter J Hotez
}

\begin{abstract}
Department of Epidemiology and Public Health, Yale University School of Medicine, 60 College Street, New Haven, CT 06520, USA *Universidad Nacional de Asuncion, Departamento de Microbiologia, Faculdad de Ciencias Medicas, Catedra de Microbiologia, Edificio Ciencias Basicas, Tte. Rodni y Guillermo Arias, Asuncion, Paraguay **Department of Epidemiology, School of Public Health, University of Michigan, 109 Observatory

Street, Ann Arbor, MI 48109, USA
\end{abstract}

A cross-sectional study in Itagua, Paraguay tested 192 people for the presence, intensity and species of hookworm infection. Fifty-nine percent of these individuals were found to be infected. Intensity of infection was determined on $92 \%$ of infected individuals by quantitative egg counts. The high intensity hookworm infections, which cause the greatest morbidity, were clustered between the ages of five and 14 years. No differences were seen between genders. The species of hookworm was determined for parasites reared from $72 \%$ of infected individuals. Both Necator americanus and Ancylostoma duodenale were identified, although the former species predominated. We conclude that hookworm infection continues to be a public health problem in Paraguay, particularly among children and adolescents who suffer from high intensity infections. A. duodenale continues to persist in the Western Hemisphere and has not been completely displaced by $\mathrm{N}$. americanus.

Key words: Necator americanus - Ancylostoma duodenale - hookworm - Paraguay - epidemiology

Human hookworm infection is a world wide public health threat affecting up to one billion people in the underdeveloped nations of the tropics and sub-tropics (Gilles 1985). Adult hookworms cause chronic blood loss by rupturing the mucosal lining of the intestine. Heavily infected individuals suffer a large blood loss that leads to chronic hookworm anemia. In children, hookworm anemia leads to profound alterations in intellectual, cognitive, and physical growth. Hookworm infection continues to be a problem in South America. In 1987, 72 million people were estimated to be infected with hookworm (Apt 1987). Most infections in Latin America were associated with the species Necator americanus ("American killer"), while Ancylostoma duodenale infections were considered rare.

Supported by the Wilbur G. Downs International Travel Fellowship and the Yale University Medical School Research Fund.

${ }^{+}$Corresponding author. Fax: +734-764-3192. E-mail: wilsonml@umich.edu

Received 13 October 1998

Accepted 12 May 1999
Hookworm was first identified as an important pathogen in Paraguay in the 1920's when Soper detected an overall prevalence of $98 \%$. Of interest was the finding that $A$. duodenale was the predominating species among isolated indigenous groups west of the Paraguay River, whereas N. americanus predominated on the east. Soper speculated that A. duodenale was the indigenous hookworm, but was gradually displaced by $N$. americanus when it was introduced east of the Paraguay River by Brazilian troops during the War of the Triple Alliance (1865-1870) (Soper 1927). Hookworm continues to be present in areas of Brazil. Recently a study in córrego do Bernardo in Minas Gerais, Brazil found hookworm prevalence to be 57\% (Webster et al. 1997). Interestingly, A. duodenale has also been found in Brazil. In a study of Grande São Paulo, Brazil, $40 \%$ of those found to be infected harbored A. duodenale (Correa et al. 1979).

Presence of $A$. duodenale is significant because it differs in modes of infection and virulence. Although both $N$. americanus and A. duodenale are transmitted through skin penetration, A. duodenale differs from $N$. americanus in that it is also transmitted through the oral route and is hypothesized to infect through maternal breast milk. In addition, A. duodenale causes a greater blood loss making it more virulent (Hotez 1989). This study examines the prevalence, intensity and predominat- 
ing species of hookworm infection among the people living in Itagua, a semi rural region $30 \mathrm{~km}$ from Asuncion.

\section{MATERIALS AND METHODS}

Fieldwork was conducted in Itagua, Paraguay from July to late August, 1996. Itagua lies on the coordinates $\mathrm{S} 57^{\circ} 04^{\prime}$ and $\mathrm{W} 26^{\circ} 09^{\prime}$, approximately $30 \mathrm{~km}$ from Asuncion. The population of Itagua is approximately 38,000 people, of which $60 \%$ are classified as rural. The population density is between 200 to 399 habitants $/ \mathrm{km}^{2}$. Adult males generally work in Asuncion while women often work selling meat from local slaughterhouses. The main spoken language of the area is Guarani, an indigenous language, although Spanish is generally understood.

Two isolated areas of Itagua, separated by approximately $3.5 \mathrm{~km}$, were chosen. All families living in the two selected areas were asked to participate. A $120 \mathrm{ml}$ volume plastic container was provided for each member of the family, with instructions to fill at least one-half of the container with feces. Each container was assigned a number, corresponding to the individual's name, age, sex and residence. Informed consent was obtained from the mother of the family, who, in turn provided family members with the numbered containers for fecal samples. All infected individuals were offered specific anthelmithic chemotherapy with either mebendazole or albendazole as per the preference of local physicians (HIC \# 8785).

Fecal samples were collected the following afternoon and processed the following morning at the Universidad Nacional de Asuncion. Samples were processed for identification of parasites using direct observation of fecal smears after concentration. Negative samples were re-examined by flotation with saturated $\mathrm{NaCl}$ solution. Quantitative egg counts were determined using the McMaster method. In order to identify hookworm species, third stage larvae were isolated by the method of Harada and Mori (1951) and then examined by light microscopy.

\section{RESULTS}

A total of 192 people from 35 families was included in the study. The compliance rate of individuals asked to participate in the study was $88 \%$. The ages of the study population ranged from 5 months to 81 years, with a mean and median age of 18 years and 10 years respectively. The age and sex distribution of the study population is shown in Fig. 1.

The overall hookworm prevalence was $59 \%$. The hookworm prevalence of males $(64 \%)$ was higher than that of females (54\%), although the

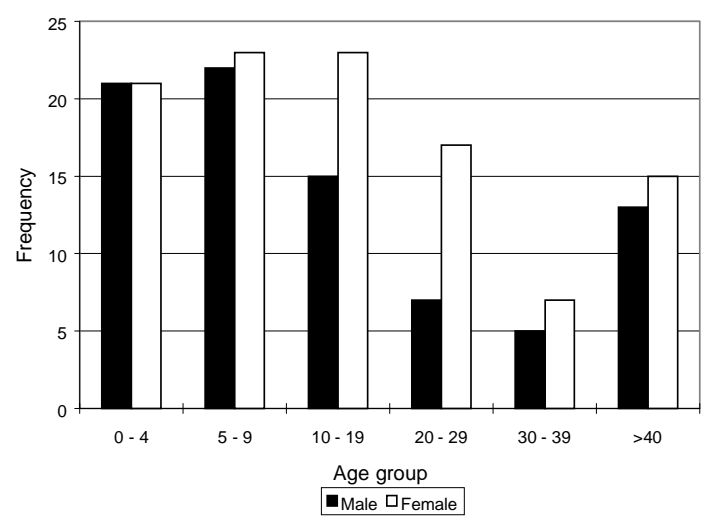

Fig. 1: age and sex distribution of the study population in Itagua, Paraguay.

difference was not statistically significant (p-value: 0.318 ). Age specific prevalence ranged from $43 \%$ ( $>40$ age group) to $79 \%$ (19-29 age group). The difference between the lowest and highest age specific prevalence was significant at a $\mathrm{p}<0.05$ level (Pearson Chi Square=7.08, p-value: 0.008). Hookworm prevalence increased with age, peaking in the 19-29 age group (Fig. 2).

Quantitative egg counts were performed on 103 of the 112 infected individuals ( $92 \%$ of the infected population). Intensity of infection ranged from 0 to 8,200 EPG. Worm burden was over-dispersed within the infected population (Fig. 3). Sixty percent of the infected population had less than 1,000 EPG, and only $9 \%$ of the population had more than 3,000 EPG. Eighty-eight percent of high intensity infections $(>3,000$ EPG) occurred between the ages of 5 and 14 (Fig. 4). A five-year-old boy had the highest quantitative egg count in the study $(8,200$ EPG). Intensity of hookworm infection did not differ by sex. Egg counts were performed on 49 and 54 males and females, respectively. The mean hookworm intensity for males was 1,139 EPG, while that of females was 1,089 EPG.

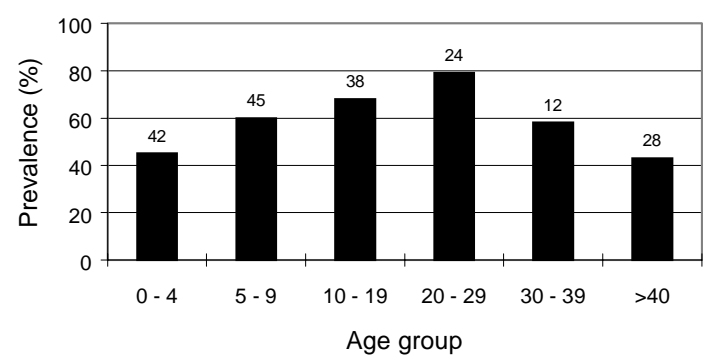

Fig. 2: age specific prevalence of hookworm infection. Numbers above bars are the total number of people in the category. 


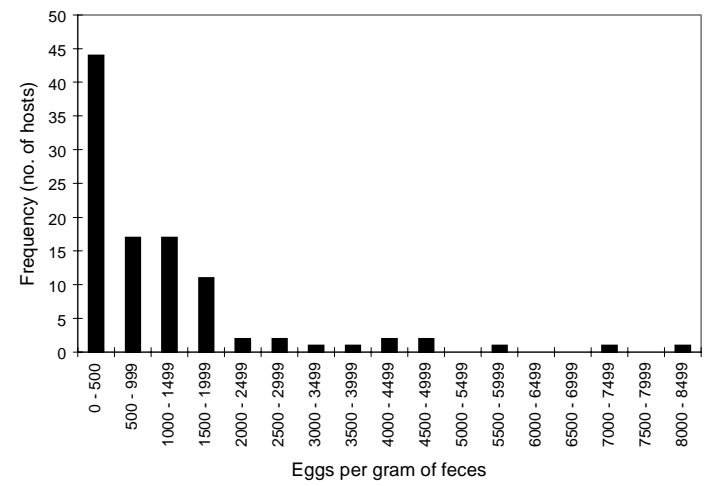

Fig. 3: distribution of hookworm burden, measured as eggs per gram among people in Itagua, Paraguay.

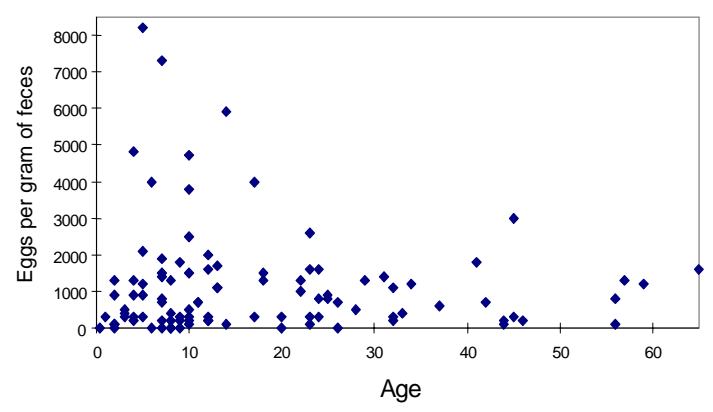

Fig. 4: relationship between age and intensity of infection.

Morphological identification of the third stage larva was used to determine the species of hookworm-infection. Species of hookworm were identified in 81 of the 112 hookworm-infected individuals ( $72 \%$ of infected population). Of those infected with hookworm $73 \%$ were infected with $N$. americanus, $15 \%$ with $A$. duodenale and $12 \%$ with both $A$. duodenale and $N$. americanus (mixed infection). Eleven out of the $12 \mathrm{~A}$. duodenale infections occurred in children less than 15 years of age. Infections with Ascaris lumbricoides and Hymenolepis nana were also observed, occurring in $8 \%$ and $7 \%$ of the population respectively.

\section{DISCUSSION}

Anthelminthic chemotherapy, education and aggressive sanitation, including the construction of latrines, resulted in the reduction of hookworm prevalence from $98 \%$ in 1924 to $47 \%$ four years later. Yet these measures have failed to eradicate hookworm from Paraguay. This study found a prevalence rate of $59 \%$ in the communities sampled. Accordingly, a study of over 10,000 individuals conducted between the years 1963 to 1975 in nine different areas of Paraguay, found an overall prevalence rate of 59\% (Canese 1992). The study population was not a random sample, rather studied everyone in two isolated areas of Itagua. Due to the high level of participation within the two areas, it is not believed that selection bias affected the results of this study. This study found that hookworm prevalence was related to age of host, but not to gender. Hookworm prevalence increased with age, reached a maximum of $79 \%$ in the 20-29 age group, then decreased.

The severity of hookworm pathology is directly related to the number of worms harbored by an individual. We found that intensity of hookworm infection exhibited an over-dispersed distribution. Although a majority of the population was infected, only $9 \%$ harbored infections greater than 3,000 EPG, putting them at greatest risk for hookwormrelated anemia. Similar patterns have been reported in other hookworm endemic areas such as Papua New Guinea (Pritchard et al. 1990), West Bengal (Nawalinski et al. 1978), and Zimbabwe (Bradley et al. 1993). Intensity of infection was determined using quantitative fecal egg counts, a commonly used indirect measure of worm burden. A weakness of this method is that very heavy infections can display a partial density dependent depression of fecundity: that is, egg output per individual worm declines as parasite burden rises (Anderson $\&$ Schad 1985). However, a recent study of Zanzabari schoolchildren found that hookworm egg counts do reflect worm burden, and indeed, were strongly and linearly related to anemia and iron deficiency anemia (Stolzfus et al. 1997).

Different age distributions of heavy infections have been reported from various study sites. Most commonly, hookworm intensity either plateaus or continues to rise through adulthood (Behnke 1987, Bundy 1989). Our study found a different pattern of worm burden. Intensity of infection increased with age through adolescents then declined in adulthood, with highest intensity infections occurring between the ages of 5 and 14. Age-intensity relationships similar to that found in our study were reported in Nigeria, where hookworm intensity peaked in the 15-19 age group then declined rapidly (Udonski 1980), and in females of West Bengal, India (Schad et al. 1975). Such an age-intensity pattern is more commonly seen in other nematode infections such as Trichuris trichura and A. lumbricoides (Bundy et al. 1987), but is rare in the case of hookworm. Differences in the age-intensity patterns of hookworm may be due to differences in the relative abundance of $N$. americanus and $A$. duodenale, perhaps because of differences in transmission dynamics of mixed infections (Behnke 1987).

Our study found continued presence of $A$. duodenale in Paraguay which is contrary to the belief that A. duodenale is an "old world hook- 
worm". It is interesting to note that $A$. duodenale occurred predominantly in children less than 15 years of age, especially when considering its additional modes of transmission and greater blood loss. High rates of Ancylostoma in Paraguay were first noted in the 1920 s, concentrated west of the Paraguay River (the Chaco). This area was considered unusual for its high ratio of $A$. duodenale-to- $N$. americanus infection (Soper 1927). Our study found that $27 \%$ of hookworm-infected individuals were infected with $A$. duodenale (15\% A. duodenale alone and $12 \%$ mixed infection). These results may under-represent of mixed infections, as in some cases only a few larvae were recovered from patients with very low egg counts.

Hookworm infection continues to be highly prevalent in Paraguay. Further studies are needed to determine why children and adolescents suffer high intensity infections relative to other populations in this region. It remains to be determined why A. duodenale infections persist in this region and has not been entirely displaced by $N$. americanus.

\section{ACKNOWLEDGEMENTS}

To Passionaria Ramos, Dirma Mesquita-Rolo and Cristian Noldin for field help. Additional support was provided through grants to Peter Hotez from the American Heart Association, the March of Dimes, Thrasher Research Fund, and the National Institute of Health (AI - 32726).

\section{REFERENCES}

Anderson RM, Schad GA 1985. Hookworm burdens and fecal egg counts: an analysis of the biological basis of variation. Trans $R$ Soc Trop Med Hyg 79: 812825.

Apt W 1987. Helmintiasis intestinales humanes en America Latina. Prevalencia actual y sus factores contribuyentes. Parasitol al Dia 11: 155-166.

Behnke JM 1987. Do hookworms elicit protective immunity in man? Parasitol Today 3: 200-206.

Bradley M, Chandiwana SK, Bundy DAP 1993. The epidemiology and control of hookworm infection in the Burma Valley area of Zimbabwe. Trans $R$ Soc Trop Med Hyg 87: 145-147.

Bund DAP 1989. Is the hookworm just another geohelminth? p. 147-165. In GA Schad, KS Warren (eds), Hookworm Disease: Current State and New Directions, Taylor \& Francis, London.

Bundy DAP, Cooper ES, Thompson DE, Didier JM, Simmons I 1987. Epidemiology and population dynamics of Ascaris lumbricoides and Trichuris trichura infection in the same community. Trans $R$ Soc Trop Med Hyg 81: 987-993.

Canese JH 1992. Estado actual de los estudios sobre la uncinariasis en el Paraguay. Ann Fac Cienc Med Univ Nac Asuncion 4: 117-162.

Correa LL, Silva MI, Silva RM, Dias RM 1979. Ancylostoma duodenale e Necator americanus diagnóstico diferencial das larvas infestantes e prevalência em amostras fecais provenientes da Grande São Paulo. Rev Inst Adolfo Lutz 39: 145-153.

Gilles HM 1985. Selective primary health care: strategies for control of disease in the developing world. XVII. Hookworm infection and anemia. Rev Infec Dis 7: 111-118.

Harada Y, Mori O 1951. A simple method for the cultivation of hookworm larvae. Igaku to seibutsugaku 20: 65-67.

Hotez PJ 1989. Hookworm disease in children. Pediatr Infec Dis J 8: 516-520.

Nawalinski T, Schad GA, Chowdhury AB 1978. Population biology of hookworms in children in rural West Bengal: general parasitological observations. Am J Trop Med Hyg 27: 1152-1161.

Pritchard DI, Quinnell RJ, Slater AFG, McKean PG, Dale DDS, Raiko A, Keymer AE 1990. Epidemiology and immunology of Necator americanus in a community in Papua New Guinea: humoral responses to excretory-secretory and cuticular collagen antigens. Parasitology 100: 317-326.

Schad GA, Chowdhury AB, Gilles HM 1975. Epidemiological and serological studies of hookworm infection in endemic areas in India and West Africa, p. 41-54. In Panel on the Use of Nuclear Techniques in Research and Control of Helminthic Infections, Nairobi, 1973, Nuclear Techniques in Helminthology Research, Int. Atomic Energy Agency, Vienna.

Soper FL 1927. The report of a nearly pure Ancylostoma duodenale infestation in native South American Indians and a discussion of its ethnological significance. Amer J Hyg 7: 174-184.

Stolzfus RJ, Chwaya HM, Tielsch JM, Schulze KJ, Albonico M, Savioli L 1997. Epidemiology of iron deficiency anemia in Zanzibari schoolchildren: the importance of hookworms. Amer J Clin Nut 65: 153159.

Udonski JK 1980. Necator americanus infection: a crosssectional study of a rural community in relation to some clinical symptoms. Ann Trop Med Parasitol 78: 443-444.

Webster M, Correa-Oliveira R, Gazzinelli G, Viana IRC, Alves de Oliveira Fraga L, Soares Silveira AM, Dunne DW 1997. Factors affecting high and low IgE responces to schistosome worm antigens in an area of Brazil endemic for Schistosoma mansoni and hookworm. Am J Trop Med Hyg 57: 487-494. 